\title{
Concomitant Immune Thrombocytopenic Purpura and Crohn's Disease
}

\section{Toru Shizuma*}

Department of Physiology, School of Medicine, Tokai University, 143, Shimokasuya, Isehara, Kanagawa, 259-1193, Japan

*Corresponding author: Toru Shizuma, Department of Physiology, School of Medicine, Tokai University, 143, Shimokasuya, Isehara, Kanagawa, 259-1193, Japan, Tel: +81-0463-93-1121; Fax: +81-0463-93-6684; E-mail: shizuma@is.icc.u-tokai.ac.jp

Received date: Jun 15, 2015, Accepted date: Aug 05, 2015, Publication date: Aug 10, 2015

Copyright: $\odot 2015$ Shizuma T. This is an open-access article distributed under the terms of the Creative Commons Attribution License, which permits unrestricted use, distribution, and reproduction in any medium, provided the original author and source are credited.

\begin{abstract}
The coexistence of immune (idiopathic) thrombocytopenic purpura (ITP) and Crohn's disease (CD) is rare. We performed a review of cases of concomitant ITP and CD in the English and Japanese literature. Among 17 identified cases of concomitant ITP and CD, ITP was initially diagnosed in four cases and CD was initially diagnosed first in six cases. Simultaneous diagnoses were reported in the remaining seven cases. No fatalities were reported in any of the 17 cases. However, resistance or transient responses to standard therapies, such as glucocorticoids or intravenous immunoglobulin (IVIG), and splenectomy for the treatment of ITP were reported in a number of concomitant cases. Moreover, the administration of anti-tumor necrosis factor (TNF)-alpha antibodies was a commonly considered pharmacological therapy in cases of concomitant ITP and CD.
\end{abstract}

Keywords: Immune thrombocytopenic purpura; Idiopathic thrombocytopenic purpura; Thrombocytopenia; Crohn's disease; Inflammatory bowel disease

\section{Introduction}

Crohn's disease (CD) and ulcerative colitis (UC) are the commonest forms of inflammatory bowel disease (IBD). CD is a chronic recurrent disease characterized by intestinal inflammation due to genetic, immunological, and environmental factors [1]. Aberrant $\mathrm{T}$ lymphocyte autoreactivity (innate and adaptive immune responses to a subset of commensal enteric bacteria) is a major component of the immunological dysfunction observed in CD patients [2]. CD involves the entire bowel wall and may affect any part of the gastrointestinal tract. Furthermore, the development of extraintestinal manifestations, including a range of autoimmune diseases, is observed in $20-40 \%$ of patients with $\mathrm{CD}[2,3]$.

Common autoimmune hematological disorders include autoimmune hemolytic anemia (AIHA), immune (or idiopathic) thrombocytopenic purpura (ITP), and pernicious anemia $[4,5]$. ITP is characterized by the presence of autoantibodies against platelet surface antigens leading to immune-mediated platelet destruction and low platelet counts [4]. Concomitant ITP and CD appears to be uncommon, with only sporadic case reports in the literature. An immunological interaction between ITP and CD has long been suspected; however, whether concomitant ITP and CD has a common immunological basis or occurs by chance remains unclear. There have been few systematic literature reviews regarding concomitant ITP and $\mathrm{CD}$. Therefore, we conducted a literature review of reported cases of concomitant ITP and CD.

\section{Methods}

We performed a review of cases of concomitant ITP and CD in the English and Japanese literature. Literature searches were performed using PubMed and Japana Centra Revuo Medicina (Igaku Chuo Zasshi) for English and Japanese manuscripts, respectively.

\section{Thrombocytopenia in CD patients}

Several conditions causing thrombocytopenia in CD patients have been reported: 1) ITP (autoimmune platelet destruction); 2) druginduced thrombocytopenia, believed to induce autoimmunity or bone marrow suppression, reported following the use of anti-tumor necrosis factor (TNF)-alpha antibodies (i.e., infliximab) [6,7], 5-aminosalicylic acid [8], azathioprine [9], and low-molecular-weight heparin [10]; 3) the presence of thrombotic thrombocytopenic purpura (TTP) or hemolytic-uremic syndrome (HUS) in patients with CD [11-13]; 4) hematological malignancies [14] or portal hypertension (hypersplenism); and 5) deficiencies in minor elements, such as copper, during nutrition therapy for $\mathrm{CD}$ [15].

\section{ITP}

ITP is characterized by systemic hemorrhagic diathesis due to excessive thrombocyte destruction. ITP can be classified into acute (newly diagnosed) and chronic types according to clinical course [16]. In general, acute ITP is more common in infants than adults and often recovers spontaneously, whereas chronic ITP is typically recurrent and occasionally refractory to therapy [16]. ITP can also be classified according to the cause as either primary ITP or secondary ITP. Primary ITP is defined as an acquired autoimmune disorder characterized by isolated thrombocytopenia in the absence of other known causes that may be associated with thrombocytopenia $[17,18]$. In contrast, secondary ITP is defined as thrombocytopenia either associated with other disorders (e.g., hematological malignancies, collagen diseases, and infectious diseases) or induced by vaccination or drugs $[17,18]$. No single test can reliably diagnose ITP. ITP is rather a diagnosis of exclusion based on medical history, physical findings, serum tests (complete blood counts and antiplatelet antibody measurements), and peripheral blood smears [17].

The diagnosis of primary ITP requires only the presence of isolated thrombocytopenia $(<100,000$ cells $/ \mu \mathrm{L})$ in the absence of obvious underlying medical conditions [17]. Although the pathogenesis of ITP has yet to be fully elucidated, immune dysregulation and the development of autoantibodies appear to play major roles in the 
Page 2 of 4

development ITP [19]. Moreover, Evans syndrome is diagnosed on the basis of the simultaneous presence or sequential occurrence of AIHA and ITP in the absence of an underlying etiology [4]. Evans syndrome is characterized by hemolytic anemia, thrombocytopenia, and the production of antibodies, complement, or both against red blood cells (RBCs) and platelets [4].

\section{Treatments for ITP}

Although glucocorticoids and intravenous immunoglobulins (IVIg) remain the major therapeutic strategies for ITP, patients may eventually develop resistance to these approaches [20]. Splenectomy may also be considered in patients developing resistance to pharmacotherapy. A number of novel treatment options have been developed over the last decade, such as rituximab [20]. Helicobacter pylori infection has been shown to be associated with ITP. Significant increases in platelet counts are commonly observed following successful eradication therapy in ITP patients infected with Helicobacter pylori [21].

\section{ITP in CD patients}

The association between ITP and UC has been well described [5]. Although the prevalence of concomitant ITP in UC patients is reportedly $0.1-0.48 \%[22,23]$, the incidence of ITP in CD patients remains unknown. Zlatanic et al. [24] presented a series of 22 cases of concomitant ITP and IBD where 19 patients had UC and only three had CD (cases were reported up to 1997).

A systematic review (40 cases of concomitant ITP and UC) by Chandra et al. [5] suggested that ITP occurs during or after the onset of colitis in many cases of concomitant ITP and UC. In majority of the cases, ITP resolved following the treatment of UC flares [5]. Therefore, the authors proposed antigenic mimicry associated with luminal antigen and platelet surface antigen as the major pathogenic mechanism underlying concomitant ITP and CD [5]. The most commonly accepted pathogenic mechanism proposes that the presence of circulating immune complexes in the serum of $\mathrm{CD}$ patients is associated with the onset of $\mathrm{CD}$ extraintestinal manifestations [25] and antigenic mimicry due to increased mucosal permeability in active colitis through enhanced exposure of the intestinal immune system to luminal antigens [24]. However, the precise mechanisms underlying concomitant ITP and CD remain unclear.

\section{Clinical characteristics of concomitant CD and ITP}

The main clinical characteristics of the 17 reported cases of concomitant ITP and CD [21-35] are summarized in Table 1. An association between ITP and CD was first reported by Kosmo et al. [27] in 1986 in a review of the English language literature, although the first report in the Japanese language literature was by Kimura et al. [26] in 1983. Of the 17 cases included in this review, 9 (53\%) were male and $8(47 \%)$ were female. CD was initially diagnosed in 6 cases, ITP in 4 cases, and both diseases were simultaneously diagnosed in the remaining 7 cases.

However, a systematic review by Chandra et al. [5] suggested that in majority of the cases of concomitant ITP and UC, ITP occurs during or after the onset of colitis. The age at diagnosis of both diseases ranged from 2 to 69 years, including five pediatric cases where both conditions were diagnoses before 16 years of age $[30,32,33]$. The interval between the diagnosis of primary and concomitant disease ranged from 0 to 28 years. No cases of concomitant Evans syndrome and $\mathrm{CD}$ were observed. All cases of $\mathrm{CD}$ predominantly affected the intestine except one case of gastric CD [35]. In two cases [22,27], the onset of ITP was apparently associated with an aggravation of CD. No fatalities were reported.

\section{Treatment of ITP in concomitant ITP and CD cases}

As described above, immunosuppressive therapies, such as glucocorticoids, IVIG, and splenectomy, are the front-line therapeutic approaches to ITP. The reported treatments and corresponding responses in reviewed cases of concomitant ITP and CD are summarized in Table 1.

All reviewed cases, except one refractory case [29], were successfully treated with the following management approaches: glucocorticoids only in 6 cases; IVIG only in 2 cases; glucocorticoids plus IVIG in 2 cases; splenectomy in 2 cases; glucocorticoids plus splenectomy in 1 case; infliximab in 2 cases; and rituximab in 1 case. Eradication therapy for Helicobacter pylori was not administered in any case following the diagnosis of ITP in concomitant cases.

\begin{tabular}{|c|c|c|c|c|c|c|c|}
\hline Case(year) & Sex & $\begin{array}{l}\text { Age at } \\
\text { diagnosis } \\
\text { of CD (years) }\end{array}$ & $\begin{array}{l}\text { Age at } \\
\text { diagnosis } \\
\text { of ITP (years) }\end{array}$ & $\begin{array}{l}\text { CD prior } \\
\text { to ITP }\end{array}$ & $\begin{array}{l}\text { Response } \\
\text { glucocorticoids }\end{array}$ & Successful treatment of ITP & References \\
\hline 1(1983) & $\mathrm{F}$ & 18 & 9 & - & + & glucocorticoids & [26] \\
\hline $2(1986)$ & $\mathrm{F}$ & 37 & 65 & + & + & glucocorticoids, splenectomy & [27] \\
\hline 3(1996) & M & 54 & 54 & - & + & glucocorticoid & [25] \\
\hline $4(1997)$ & M & 43 & 43 & $\operatorname{Sim}$ & + & glucocorticoid & [28] \\
\hline $5(1997)$ & $\mathrm{F}$ & 22 & 22 & Sim & + & glucocorticoid & [24] \\
\hline 6(1998) & $\mathrm{F}$ & 19 & 19 & Sim & - & & [29] \\
\hline $7(2000)$ & $\mathrm{F}$ & 8 & 17 & + & - & IVIG & [22] \\
\hline $8(2001)$ & M & 12 & 14 & + & - & IVIG & [30] \\
\hline $9(2001)$ & M & 2 & 2 & + & + & glucocorticoids & [30] \\
\hline
\end{tabular}


Page 3 of 4

\begin{tabular}{|c|c|c|c|c|c|c|c|}
\hline 10(2001) & $\mathrm{F}$ & 11 & 5 & - & - & splenectomy & [30] \\
\hline $11(2003)$ & $\mathrm{F}$ & 25 & 25 & Sim & - & Rituximab & [31] \\
\hline 12(2005) & M & 5 & 3 & - & transient & splenectomy & [32] \\
\hline 13(2006) & M & 5 & 5 & Sim & + & glucocorticoids, IVIG & [33] \\
\hline $14(2006)$ & M & 44 & 44 & Sim & + & glucocorticoids, IVIG & [23] \\
\hline $15(2007)$ & $\mathrm{F}$ & 69 & 69 & + & - & Infliximab & [21] \\
\hline $16(2008)$ & $M$ & 28 & 38 & + & $?$ & Infliximab & [34] \\
\hline $17(2013)$ & $M$ & 57 & 57 & Sim & + & glucocorticoids & [35] \\
\hline
\end{tabular}

Table 1: Characteristics of 17 Patients with Comorbid Crohn's Disease and Immune Thrombocytopenic Purpura.

\section{Anti-TNF-alpha antibodies for the treatment of concomitant ITP and CD}

The mucosal production of type 1 helper $\mathrm{T}$ cells $\left(\mathrm{T}_{\mathrm{h}} 1\right)$ proinflammatory cytokines, such as TNF-alpha, is known to be increased in $\mathrm{CD}[2,21]$. Moreover, $\mathrm{T}_{\mathrm{h}} 1$ responses may mediate both acute ITP and CD [21]. As discussed above, remission was achieved in two cases concomitant ITP and CD following the administration of infliximab (anti-TNF-alpha antibodies) [21,34].

Anti-TNF-alpha antibodies, such as infliximab, target both monocytes and activated $\mathrm{T}$ lymphocytes. Potential mechanisms of action of anti-TNF-alpha therapies include apoptotic and cytotoxic effects on monocytes and macrophages (the major producers of soluble TNF-alpha) and subsequent decreases in antiplatelet antibody production by B lymphocytes [2,21]. De Rossi et al. [34] proposed the use of anti-TNF-alpha antibodies as an efficient and relatively costefficient treatment in cases of ITP, particularly when concomitant with CD. Infliximab may be considered in patients refractory to standard therapies for concomitant CD and ITP $[2,34,35]$.

\section{Conclusion}

Although there are currently a limited number of case reports describing concomitant ITP and CD, no clear tendency of one disease preceding the other, or differences in gender susceptibility, were found in our review of the literature. However, a number of reports suggested a correlation between the occurrence of ITP and CD activity. Whether concomitant ITP and CD occur incidentally or reflect a shared genetic or immunological basis remains unknown. Further investigations are required to fully elucidate the relationship between ITP and CD.

\section{References}

1. Fakhoury M, Negrulj R2, Mooranian A2, Al-Salami H2 (2014) Inflammatory bowel disease: clinical aspects and treatments. J Inflamm Res 7: 113-120.

2. Lazaraki G, Metallidis S, Giannoulis K, Tarpagos A, Germanidis G (2007) Infliximab: an alternative treatment for refractory immune thrombocytopenic purpura related to Crohn's disease? Inflamm Bowel Dis 13: $1452-1453$.
3. Park BS, Park S, Jin K, Kim YM2, Park KM3, et al. (2014) Coombs negative autoimmune hemolytic anemia in Crohn's disease. Am J Case Rep 15: 550-553.

4. Korkmaz H, Bugdaci MS, Temel T, Dagli M, Karabagli P (2013) Autoimmune hepatitis-primary biliary cirrhosis overlap syndrome concomitant with immune hemolytic anemia and immune thrombocytopenic purpura (Evans syndrome). Clin Res Hepatol Gastroenterol 37: e45-50.

5. Chandra S, Finn S, Obah E1 (2014) Immune thrombocytopenic purpura in ulcerative colitis: a case report and systematic review. J Community Hosp Intern Med Perspect 4.

6. Casanova MJ, Chaparro M, Martínez S, Vicuña I, Gisbert JP (2012) Severe adalimumab-induced thrombocytopenia in a patient with Crohn's disease. J Crohns Colitis 6: 1034-1037.

7. Selby LA, Hess D, Shashidar H, de Villiers WJ, Selby LA (2004) Crohn's disease, infliximab and idiopathic thrombocytopenic purpura. Inflamm Bowel Dis 10: 698-700.

8. Kotanagi H, Ito M, Koyama K, Chiba M (1998) Pancytopenia associated with 5-aminosalicylic acid use in a patient with Crohn's disease. J Gastroenterol 33: 571-574.

9. Connell WR, Kamm MA, Ritchie JK, Lennard-Jones JE (1993) Bone marrow toxicity caused by azathioprine in inflammatory bowel disease: 27 years of experience. Gut 34: 1081-1085.

10. Dager WE, White RH (2004) Low-molecular-weight heparin-induced thrombocytopenia in a child. Ann Pharmacother 38: 247-250.

11. Winwood PJ, Iredale JP, Williamson PJ, Lesna M, Loehry CA (1992) Thrombotic thrombocytopenic purpura mimicking acute small bowel Crohn's disease. Gut 33: 857-859.

12. Peraldi MN, Akposso K, Haymann JP, Lahlou A, Sraer JD (1997) Haemolytic-uraemic syndrome in patients with Crohn's disease. Nephrol Dial Transplant 12: 2744-2745.

13. Park SJ, Park JE, Jang JY, Shin JI (2011) The significance of interleukin 12 and interferon-gamma in thrombotic thrombocytopenic purpura/ hemolytic uremic syndrome and Crohn's disease. Ren Fail 33: 639-640.

14. Orii S, Sugai T, Nakano O, Yoshinari H, Sato S (1991) Acute promyelocytic leukemia in Crohn's disease. Case report and review of the literature. J Clin Gastroenterol 13: 325-327.

15. Spiegel JE, Willenbucher RF (1999) Rapid development of severe copper deficiency in a patient with Crohn's disease receiving parenteral nutrition. JPEN J Parenter Enteral Nutr 23: 169-172.

16. Casoli P, Tumiati B (1989) [Acute idiopathic thrombocytopenic purpura after anti-influenza vaccination]. Medicina (Firenze) 9: 417-418.

17. Lo E, Deane S2 (2014) Diagnosis and classification of immune-mediated thrombocytopenia. Autoimmun Rev 13: 577-583. 
Citation: Shizuma T (2015) Concomitant Immune Thrombocytopenic Purpura and Crohn's Disease. J Blood Disord Transfus 6: 295. doi: 10.4172/2155-9864.1000295

Page 4 of 4

18. McKenzie CG, Guo L, Freedman J, Semple JW (2013) Cellular immune dysfunction in immune thrombocytopenia (ITP). Br J Haematol 163: 10-23.

19. Chong BH, Ho SJ (2005) Autoimmune thrombocytopenia. J Thromb Haemost 3: 1763-1772.

20. Ozkan MC, Sahin F, Saydam G1 (2015) Immune thrombocytopenic purpura: new biological therapy of an old disease. Curr Med Chem 22: 1956-1962.

21. Germanidis G, Lazaraki G, Gintikas S, Karayannis D, Mikoudi K, et al. (2007) Refractory Crohn-associated acute immune thrombocytopenic purpura treated with infliximab A proposed pathogenetic mechanism. Eur J Intern Med 18: 344-346.

22. Boyne MS, Dye KR (2000) Crohn's colitis and idiopathic thrombocytopenic purpura. Postgrad Med J 76: 299-300.

23. Tsibouris P, Kapsoritakis AN, Bouronikou E, Boulbou M, Kyriakou D, et al. (2006) Crohn's disease associated with severe autoimmune thrombocytopenic purpura. Inflamm Bowel Dis 12: 1188-1189.

24. Arruda VR, Montes CG, Sevá-Pereira A, Annicchino-Bizzacchi JM (1997) Association of severe autoimmune thrombocytopenic purpura and Crohn's disease. Am J Gastroenterol 92: 2285-2288.

25. Manzano ML, Yela C, Castellano G, Rodriguez S, Solis JA (1996) Idiopathic thrombocytopenic purpura and pancytopenia in a patient with Crohn's disease: a new association. Am J Gastroenterol 91: 1678-1679.

26. Kimura A, Ono E, Hiyoshi Y, Fujimoto T, Yamashita F, Hayashida K (1983) A case of a female infant complicated with Crohn's disease, antinuclear antibody-positive, and hypocomplementemia after splenectomy for idiopathic thrombocytopenic purpura. Japanese Journal of Pediatrics 36: 53-57.

27. Kosmo MA, Bordin G, Tani P, McMillan R (1986) Immune thrombocytopenia and Crohn's disease. Ann Intern Med 104: 136.
28. Zlatanic J, Korelitz BI, Wisch N, Kim P, Ammirati M, et al. (1997) Inflammatory bowel disease and immune thrombocytopenic purpura: is there a correlation? Am J Gastroenterol 92: 1948-1949.

29. Baudard M, Molina T, Benfiguig K, Bethoux JP, Zittoun R (1998) Idiopathic thrombocytopenic purpura associated with Crohn's disease. Haematologica 83: 92-93.

30. Higuchi LM, Joffe S, Neufeld EJ, Weisdorf S, Rosh J, et al. (2001) Inflammatory bowel disease associated with immune thrombocytopenic purpura in children. J Pediatr Gastroenterol Nutr 33: 582-587.

31. Papadakis KA, Rosenbloom B, Targan SR (2003) Anti-CD20 chimeric monoclonal antibody (rituximab) treatment of immune-mediated thrombocytopenia associated with Crohn's disease. Gastroenterology 124: 583.

32. KuloÄŸlu Z, Kansu A, DemirÃßeken F, Ileri T, Ertem M, et al. (2005) The association of chronic recurrent immune thrombocytopenic purpura and Crohn's disease. Inflamm Bowel Dis 11: 950-951.

33. Motamed F, Zandieh F, Sedighi M (2006) Crohn's disease and idiopathic thrombocytopenic purpura in a patient with ectodermal dysplasia and immunodeficiency. Iran J Allergy Asthma Immunol 5: 143-145.

34. de Rossi TM, Krauss N, Voll RE, Nägel A, Weidenhiller M, et al. (2008) Long-term partial remission of autoimmune thrombocytopenia in a patient treated with the anti-tumor necrosis factor-alpha antibody infliximab for refractory fistulizing Crohn's disease. Digestion 78: 195-200.

35. Shaaban H, Maroules M (2013) A rare case of gastric Crohn's disease associated with immune thrombocytopenic purpura. J Crohns Colitis 7: e401-402. 